\title{
REPENSANDO O FUTURO DA ÁGUA EM NOSSO PLANETA
}

\section{ARTIGO DE REVISÃO}

DIAS, Deusira Nunes Di Lauro ${ }^{1}$

DIAS, Adailton Di Lauro²

DIAS, Deusira Nunes Di Lauro. DIAS, Adailton Di Lauro. Repensando o futuro da Água em nosso planeta. Revista Científica Multidisciplinar Núcleo do Conhecimento. Ano 04, Ed. 08, Vol. 06, pp. 19-32. Agosto de 2019. ISSN: 2448-0959

\section{RESUMO}

Considerada o líquido mais importante, precioso e indispensável para a sobrevivência da vida humana na terra, a água tem sido motivo de constante preocupação, pois a forma como a sociedade tem se apropriado e utilizado os recursos hídricos no planeta tem comprometido a qualidade, bem como o acesso de muitas comunidades a esse recurso vital para a manutenção da vida. Nesse trabalho pretende-se analisar e discutir estratégias que garantam a preservação e o uso sustentável da água no planeta, abordando que, em algumas regiões do Brasil e do mundo, já se encontram com extrema escassez de água e, segundo alguns autores, este problema tende a se agravar cada vez mais devido a vários fatores, e os principais são o rápido crescimento da população e a grande demanda por alimentos no mundo. As leis que regem os recursos hídricos estão sendo cada vez mais ajustadas, a fim de preservar

${ }^{1}$ Graduada no Curso de Letras pela Universidade Estadual da Bahia - UNEB Campus X ; Pós graduada em Língua Portuguesa pela Universidade Vale do Cricaré e aluna regular do Curso de Mestrado em Educação pela Universidade Internacional Unigrendal On-line.

2 Graduado em Letras pela Uneb, Graduado em Língua Inglesa pela Unimes, PósGraduado pelas Faculdades Integradas de Jacarepaguá(FIG), e aluno regular do Curso de Mestrado em Educação pela Universidade Internacional Unigrendal On-line. 
os recursos hídricos e todo o meio ambiente. O Brasil tem demonstrado que é preciso preservar, no entanto muito ainda há de ser feito para minimizar os impactos causados pelo homem ao meio ambiente.

Palavras-Chave: Água, escassez, preservação, sustentabilidade.

\section{INTRODUÇÃO}

A humanidade tem alcançado, principalmente neste século, inúmeras conquistas jamais imaginadas pela ciência e tecnologia. No entanto, a problemática da água e da manutenção da vida no planeta tem levado boa parte da população mundial a se perguntar sobre o que fazer para garantir que todos tenham acesso a água, mas nem sempre se tem uma resposta, pois o ser humano nem sempre ou quase nunca se dá conta da necessidade de preservação desse bem tão precioso.

Tal preocupação diante do futuro não se dá por acaso, afinal, os dados sobre a distribuição, reserva e disponibilidade da água no planeta evidenciam a necessidade de se buscar alternativas de preservação, tal como discorre VICTORINO:

Sabe-se que quase toda a superfície do planeta Terra está coberta por água: dos oceanos, dos rios e lagos, arroios e sangas. Água das calotas polares em forma de gelo, água da chuva, muita, muita água... Mas, na realidade nem tudo é azul (a cor que cobre a Terra - devido à água quando é vista do espaço), porque toda a água do planeta (1.370.000.000 km³) é constituída basicamente de dois tipos: água salgada dos mares e água doce dos rios, lagos e subsolo. No entanto, $97 \%$ do total é ocupado por água salgada, imprópria para o consumo. Com o chamado "ciclo das águas" (processo de evaporação e retorno da água para a superfície em forma de chuva, neve, granizo ou geada), a água se recompõe nas diversas formas dando vida às plantas $e$ gerando diversos biomas seguindo o curso natural da vida. A natureza é sábia e justa pois quando a água escapa para a atmosfera em forma de evaporação, a transpiração é compensada com a precipitação. Essa 
diferença entre volume de água que cai e volume de água que evapora é de cerca de 45 mil quilômetros cúbicos por ano - o que, em tese, o ser humano poderia gastar. Só que, desse total, apenas $20 \%$ é aproveitável. A água utilizável está nos rios, nos lagos, nas águas da chuva e na água subterrânea. No entanto, elas todas juntas correspondem a apenas $1 \%$ do volume de água doce (VICTORINO, 2007, p.16).

Figura 1 - Gráfico - "Distribuição das águas na Terra"

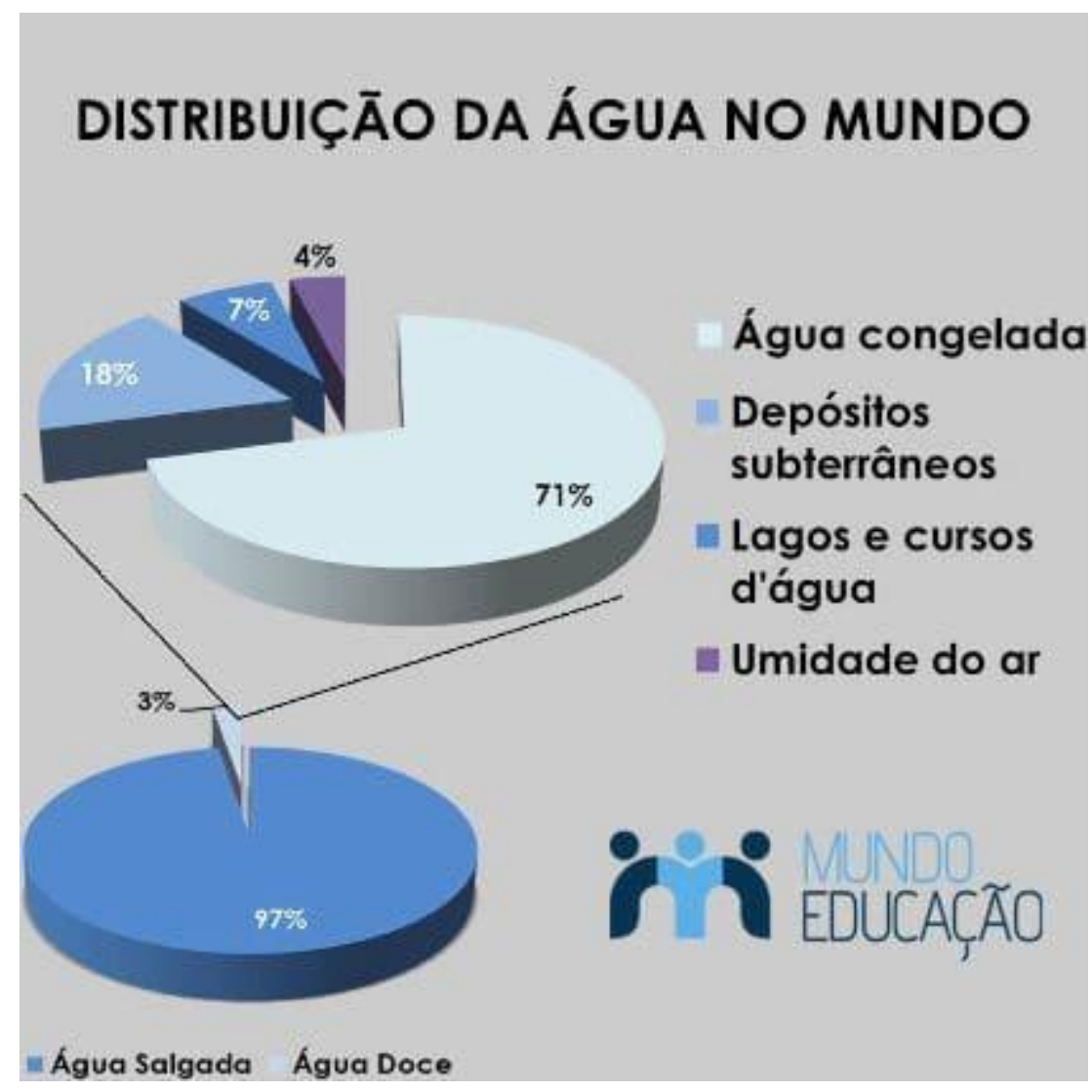

(Fonte: Site Mundo Educação)

Ao analisarmos o gráfico acima, observa-se que a quantidade de água disponível para o uso é insuficiente, uma vez que:

Se juntarmos 1,5 litro de água, como a encontramos no planeta, e a dividirmos proporcionalmente, a quantidade de água doce disponível seria equivalente a uma única e insignificante gota. E para complicar, 
esse pouco restante está cada vez mais poluído, especialmente nas grandes cidades, devido ao aumento da população mundial que, só no século passado tornou-se três vezes maior, o que ocasionou o aumento de fábricas, mais desperdício e mais irrigação nas lavouras. De acordo com o Banco Mundial, cerca de 80 países enfrentam hoje problemas de abastecimento. A situação mais crítica está na Ásia onde, $60 \%$ da população vive com apenas $32 \%$ da água doce disponível (VICTORINO, p. 17).

Ao analisarmos todos estes dados, é possível avaliar a gravidade dos impactos causados pelas ações do homem ao meio ambiente e, especificamente à água, que é considerada um recurso vital para a vida na terra. Muitos países inclusive, já têm adotado posturas de contenção e preservação, através de tratados, acordos, a fim de minimizar tais impactos. No entanto, uma parcela considerável da população mundial ainda ignora que o futuro está ameaçado e que será necessário haver uma mudança, não apenas de mentalidade, mas também de atitude em relação ao uso desse recurso que tem sido utilizado de forma irresponsável ao longo da história.

Sabe-se que a população mundial tem crescido de forma desordenada, e isso demanda também um aumento considerável da produção agrícola industrial na tentativa de garantir alimento para todos, o que impõe pressões cada vez mais intensas sobre o meio ambiente. Diante disso, faz-se necessário encontrar estratégias que anulem os impactos, pois, está prevista uma população superior a oito bilhões de pessoas para o ano de 2020: 65\% em áreas litorâneas e 60\% em cidades com mais de 2,5 milhões de pessoas. Além disso, a utilização da provisão de água aumentou enormemente em um curto período de tempo: enquanto a renovação não alterou o nível dos recursos hídricos, de 1900 a 1995, em contra partida, a quantidade utilizada aumentou para seis vezes mais (duas vezes mais o índice de aumento populacional) e duas vezes mais desde 1975. Do total de água consumida no planeta, a agricultura absorve uma média mundial de $70 \%$ das provisões de água, e nos países subdesenvolvidos a porcentagem é ainda maior registrando um aumento de 80 a $90 \%$, sendo uma média de $20 \%$ para a indústria e $10 \%$ para usos domésticos e outros. 
Ao analisarmos a situação do Brasil dentro deste contexto, fica ainda mais evidente que a água não tem sido utilizada de forma racional, o que compromete e muito o abastecimento e a qualidade de vida em muitas regiões do país.

\section{CONSUMO DE ÁGUA NO PAÍS}

Figura 2- Gráfico - Consumo de água no país

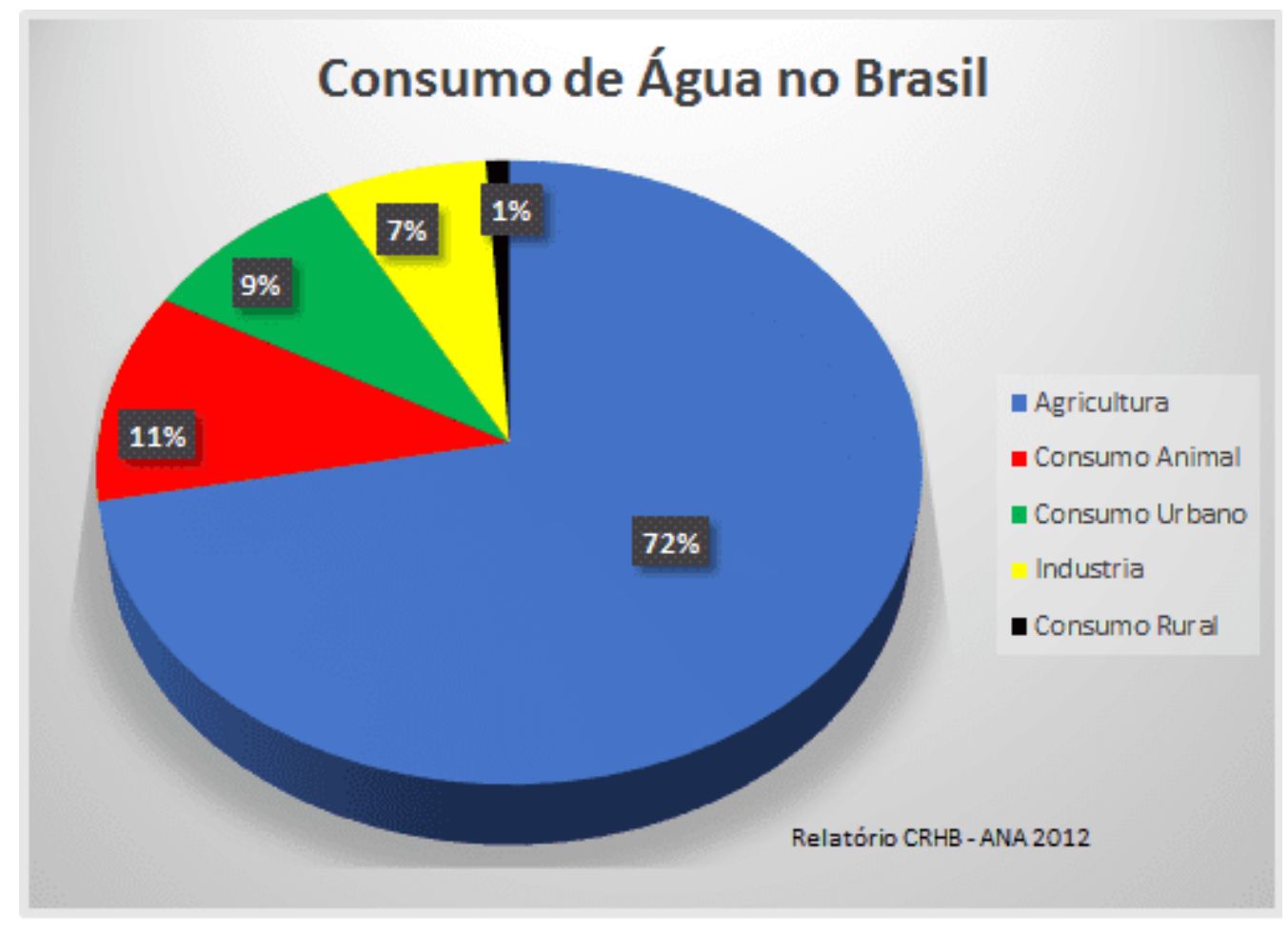

(Fonte: EOS consultores)

O gráfico acima nos aponta a agricultura como a grande vilã no consumo e desperdício da água no Brasil e, embora o país seja pioneiro em aprovação de leis que limitam o consumo e impõe algumas sanções aos que cometem abusos no consumo e na utilização da água, sabe-se também que não há fiscalização suficiente por parte dos governantes para garantir que as leis sejam respeitadas, ou seja, embora existam leis de preservação, na prática está longe de acontecer.

Atualmente, apesar do conceito jurídico de bem de uso comum do povo, a água é um recurso, para muitos, de valor econômico. Isto resulta do crescimento da demanda 
por água para os diversos usos, que acompanha o desenvolvimento urbano e industrial dos países. Nos dias de hoje, os grandes problemas ligados à água não acontecem por causa da natureza, mas surgem da má utilização com desperdício e imprevidência, bem como a poluição generalizada que ameaça o meio ambiente.

O Código de Águas, lei maior que disciplina o aproveitamento das águas no Brasil é de 10 de julho de 1934, já tem certa idade, mas nem por isso deixa de ser atual porque classifica as categorias jurídicas, discrimina os usos da água e respectivos preceitos e, sobretudo: procura assegurar os interesses gerais da sociedade. No antigo código era possível encontrar domínio privado da água em alguns casos, mas isto foi extinto a partir de outubro de 1988, quando todos os corpos d'água passaram a ser de domínio público.

\section{A QUALIDADE DA ÁGUA QUE CONSUMIMOS}

A qualidade da água disponível no planeta é outro aspecto que também tem sido alvo de preocupação por parte dos órgãos de saúde no mundo inteiro já que doenças são evitadas quando do uso de água descontaminada. A qualidade da água decidiu a sorte de algumas regiões em todo o mundo em caráter econômico, principalmente em relação à fabricação de cervejas. Mas não é só no ramo das cervejarias que a pureza da água é importante, ela é necessária também nas indústrias de tapeçarias, em curtumes, na indústria de tecidos e nas pedras preciosas. Além disso, a qualidade da água irá determinar qualidade de vida de seus consumidores. Quando não se tem água potável própria para o consumo humano, o resultado é o alto índice de doenças e demais problemas decorrentes delas. Esta é uma preocupação que no passado determinava o sucesso ou o fracasso das nações mais desenvolvidas, como afirma Célia Jurema:

O homem sempre se preocupou com a água. Já há 4.000 anos a.C., as primeiras leis que se tem conhecimento eram códigos que regulavam o uso das águas, escritas pelos sumérios. Mas, nem todas as civilizações foram cuidadosas quanto a isso. Registros mostram que os Maias tiveram que abandonar a cidade de Tical, localizada em plena mata 
tropical, onde se encontram as ruínas da Pirâmide do Sol, porque não souberam armazenar corretamente a água, além de produzirem erosões cada vez maiores e grandes desmatamentos porque usavam madeira até nas estruturas internas das colunas de seus gigantescos templos. No México, na península de Yucatan, o deus da chuva, Chac, era reverenciado e, sempre que a água se tornava escassa, novos templos eram erguidos na esperança de que o deus das águas salvasse os Maias das secas. São encontrados com frequência, motivos do deus da chuva maia na base das pirâmides. A convivência com os rios trouxe sabedoria às populações ao longo do desenvolvimento da humanidade, os faraós, planejavam suas cidades deixando livres as áreas ribeirinhas" (VICTORINO, 2007, p. 19).

Desde tempos mais remotos, a água sempre foi um dos reguladores sociais mais importantes. As estruturas das sociedades camponesas e das comunidades aldeãs, onde as condições de vida estão intimamente ligadas ao solo, eram organizadas em torno da água. Eram raros os casos em que todos os membros de uma comunidade estivessem em um mesmo nível em relação à água - o acesso a ela quase sempre envolveu desigualdade. Isso nos leva a compreender como é o relacionamento dos seres humanos com a água e de um com o outro devido à água. O homem, porém, levou muito tempo para se importar e se preocupar efetivamente com a qualidade da água - muitos ainda hoje não se deram conta de que, mais dia menos dia, a escassez será uma realidade, e continuam a usar a água de forma indiscriminada seja para tarefas simples como lavar o carro com mangueira ou varrer a calçada com jatos d'água. Outros, ainda, jogam todo tipo de resíduos nos lagos, rios e riachos. Até quando a sociedade vai continuar a agir de forma tão inconsequente e irresponsável? A água, esse mineral que tanto conhecemos e que faz parte de nós, existe há pelo menos 3,9 bilhões de anos. O "ser racional", em poucas gerações, já conseguiu comprometer, não só a qualidade, mas, também, a quantidade desse manancial natural. Pode-se avaliar o grau de desenvolvimento de um povo pela qualidade da água e dos serviços de saneamento que são oferecidos à população. A capacidade de suporte para a vida humana e para a sociedade é complexa, dinâmica e sofre 
variações de acordo como o homem maneja os recursos ambientais. É estranho que os sábios sacerdotes da antiguidade não tivessem percebido as correlações existentes entre o suprimento de água e a conservação das florestas. Naquela época, o plantio era privilégio somente dos príncipes, não passava por suas 'brilhantes' cabeças que seriam necessárias frentes de plantadores para reflorestar as terras devastadas:

Há oito mil anos, o Brasil possuía 9,8\% das florestas mundiais. No início do Século XXI, essa porcentagem caiu para $28 \%$ e, o que é pior, dos 64 milhões de quilômetros quadrados de florestas existentes antes da expansão demográfica e tecnológica dos humanos restam menos de 15,5 milhões, cerca de $24 \%$. Isto significa que mais de $75 \%$ das florestas do mundo já desapareceram...(EBC)

Restaurar os recursos naturais degradados é mais difícil do que sua conservação; e, muitos deles, como a água, não se consegue restaurar, quando acaba não tem volta, quando termina é para sempre. A falsa ilusão de que a água nunca terá fim aparente na natureza talvez justifique, em parte, a negligência histórica dos seres humanos nas suas relações com os recursos hídricos. Sabe-se que não existe tanta água potável disponível como a paisagem nos faz ver. O que na realidade temos como água potável é apenas $0,03 \%$ do total de água do planeta. Essa insignificante quantia deveria receber todos os cuidados possíveis, no entanto, não é isso o que vemos em quase todos os continentes, afinal, os principais aquíferos estão sendo exauridos com uma rapidez maior do que sua capacidade natural de se recompor.

\section{O USO INDISCRIMINADO DA ÁGUA E O COMPROMETIMENTO DA QUALIDADE DE VIDA DA HUMANIDADE}

Não é preciso ir muito longe para perceber situações de desperdício e desvalorização dos recursos naturais. Com a água não deixa de ser igual, e na teoria a ideia de preservação deste recurso apesar de ser de certa forma enfatizada, na prática não se vê grande mobilização para prevenir consequências previsíveis de um futuro com escassez de água. A citação a seguir, define claramente a situação em questão: 
Um dos principais desafios da sociedade neste século 21 , diz respeito a premente necessidade da preservação dos recursos hídricos em qualidade e quantidade, num cenário de aumento populacional e de baixa sustentabilidade dos processos produtivos e do consumo.

[...]Essas previsões de crescimento populacional e estimativas vinculadas a produção, conservação e distribuição de alimentos consideram que se a população mundial atingir 10 bilhões de habitantes nos próximos 50 anos, teremos $70 \%$ dos habitantes do planeta enfrentando deficiências no suprimento de água, repercutindo em cerca de 1,06 bilhões de pessoas que não terão água sequer para alimentação básica (SILVA, 2009, p.1).

Enquanto em muitos países espalhados pelo mundo a água já se tornou uma disputa gerando conflitos diversos, o Brasil ainda não se deu conta da grande responsabilidade que temos com a qualidade de vida das gerações futuras. De acordo com Célia Jurema Aito, o Brasil é um país privilegiado em termos de disponibilidade de água pois conta-se com $28 \%$ da disponibilidade sul-americana e de $12 \%$ das reservas de água do mundo. Em território brasileiro, $72 \%$ da água está localizada na bacia amazônica. O Rio Amazonas tem 6.885 quilômetros de extensão e é o maior do mundo em volume de água, despejando 175 milhões de litros por segundo no Oceano Atlântico. No entanto, não se pode esquecer que o crescimento da população faz com que o risco de escassez também nos atinja. Ainda segundo Célia Jurema, entre 1970 e 2000 o Brasil passou de uma população urbana de $55 \%$ para $82 \%$ do total da população. Sabe-se que mais de 1,4 bilhão de pessoas não têm acesso à água potável e, ainda, outros 2 bilhões não têm qualquer tipo de saneamento básico.

À medida que o homem moderno evoluiu em tecnologia, deixou de ter contato com sua essência natural, passou a viver cada vez mais longe de sua base, a natureza, e a se transformar em um ser ansioso e irritado. $O$ desequilíbrio coletivo que o nosso planeta enfrenta representa profundamente um desequilíbrio dos próprios indivíduos que compõem a população mundial. Tal desequilíbrio relaciona-se a uma falha no processo de evolução do homem que distanciando-se das suas origens, busca, na 
maioria das vezes, o seu bem estar individual, esquecendo-se de que somos parte de um organismo vivo chamado "sociedade" e para que ela se desenvolva de forma eficaz, faz-se necessário garantir o bem de todos e não apenas de si próprio. Nas grandes cidades, percebe-se que cada vez mais pessoas sentem-se sozinhos, desamparados, mesmo vivendo em meio à multidão, o que as tornam cada dia mais individualistas e egoístas. E embora na atualidade, haja uma ideia de preservação, pelo menos nas propagandas de muitas empresas que visam levantar a bandeira da preservação um "marketing empresarial” que é rentável, a grande verdade é que pouco fazem pela preservação do meio ambiente e consequentemente da água no país. Daí se sentir a ineficiência, apesar de tantos esforços, dos nossos governantes, das organizações não governamentais e até mesmo da própria população em relação à questão ambiental, uma vez que todo o trabalho é realizado basicamente para resolver os problemas externos, quando o processo de mudança e aperfeiçoamento deve começar a nível interno de cada pessoa.

Infelizmente, a população mundial que ocupa cada vez mais espaço no planeta é diretamente responsável pela degradação de rios, áreas costeiras, oceanos, praias e, como essa população não para de crescer, o volume do lixo vem se tornando maior a cada dia que passa. Para se ter uma ideia do problema, só os americanos produzem por ano 212 milhões de toneladas de lixo e movimentam quase 3 milhões de garrafas plásticas por hora. É preciso a consciência de dispor este tipo de lixo em locais para reciclagem. No Brasil, a Política Nacional de Resíduos Sólidos (Lee Federal 12.305/2010) determina que todo material produzido pelas atividades domésticas e comerciais que serão possíveis de coleta pelos serviços de limpeza pública, deve ser encaminhado para destinação final apenas quando não é possível seu reaproveitamento, seja por meio da reciclagem, da reutilização, da compostagem ou da geração de energia. Quando não existir tecnologias viáveis os resíduos devem ser destinados a aterros sanitários. Entretanto, do volume produzido em 2016, quase 30 milhões de toneladas não tiveram a destinação adequada, o que representa um percentual de $41,6 \%$ do total gerado, o que transforma os resíduos sólidos em um grave problema ambiental, pois o descarte inadequado pode carregar esse material 
para os córregos e rios e consequentemente, alcança os oceanos, além da problemática dos lixões, os impactos na saúde pública dentre outros efeitos negativos.

Em média 80 milhões de toneladas de resíduos sólidos urbanos são produzidos, sendo quase 470 quilos por habitante, onde $60 \%$ desse total é de material reciclável. No entanto, apenas $3 \%$ do lixo produzido é encaminhado para reciclagem.

A impressão que se tem é de que em todos os lugares as águas superficiais estão sendo poluídas com uma variedade assustadora de resíduos urbanos, industriais e agrícolas. Mesmo em países industrializados, onde vigora a legislação sobre a qualidade da água, a poluição ainda é um problema que incomoda. Nos Estados Unidos, descobriu-se que $60 \%$ dos lagos pesquisados estão poluídos por nutrientes de fertilizantes e dejetos animais, o que vem causar a morte quase que maciça de peixes, além da degradação da qualidade da água. No Canadá, 20 mil lagos são atingidos por chuvas ácidas.

O crescimento demográfico e econômico do Brasil nos últimos anos utilizou os recursos hídricos muito além de sua capacidade de suporte tanto em quantidade como em qualidade. Os sérios problemas de gerenciamento da água são provocados pela expansão desordenada das populações urbanas e a disponibilidade restrita de recursos hídricos, além disso, as políticas públicas destinadas à preservação da água são insuficientes diante da demanda do consumo e utilização. A ocupação dos espaços planos, próximos aos rios e sem controle, ocasionou durante anos e anos, pequenas inundações em um grande número de cidades do Sul e Sudeste, no Brasil. Nos anos 80, várias inundações ribeirinhas aconteceram e com grandes prejuízos, principalmente no Paraná, Santa Catarina, São Paulo e Minas Gerais. Em nosso país se verifica uma grande diversidade de situações, com abundância de recursos hídricos nas regiões Norte e Centro-Oeste e escassez nas regiões Nordeste e Sudeste, em contraposição à maior concentração da demanda, juntamente com a região Sul. O desenvolvimento urbano também faz com que aumentem as áreas impermeáveis e de pouca absorção da água através de residências, passeios, ruas, estacionamentos e até mesmo os parques. Como a água das chuvas não consegue se infiltrar no solo, automaticamente, o volume adicional escoa para o sistema de 
drenagem em direção aos rios. Na década de 70 , havia grande esperança de que fosse possível planejar o crescimento das cidades e planejar harmonicamente seu futuro. Porém, 37 anos depois, constata-se que o planejamento urbano no Brasil, ou mesmo no exterior, foi atrofiado levando à acumulação dos problemas.

A orla marítima brasileira é vítima da fúria imobiliária, principalmente no Rio de Janeiro, além das praias do Nordeste e do Sul. O crescimento desenfreado proporciona o surgimento das vilas e favelas onde não se encontra água potável e, muito menos, esgoto. Rio de Janeiro e São Paulo, as duas maiores cidades brasileiras, possuem déficits sérios de rede de tratamento de esgoto e, apesar de terem empréstimos internacionais, não conseguem diminuir o nível altíssimo de poluição da Baía de Guanabara e do Rio Tietê, isso devido à falta de conscientização da população e de um programa de educação ambiental que estimule mudanças de comportamento dos indivíduos.

As maiores cidades do país gerenciam mal seus recursos hídricos. Em 1997, o Banco Mundial ofereceu US $\$ 40$ bilhões para as empresas de saneamento. Quase $100 \%$ do dinheiro ainda permanecem intactos porque as empresas brasileiras não se enquadram nas exigências técnicas mínimas para receber empréstimos - afirmação do geólogo Aldo Rebouças, da Companhia de Pesquisa de Recursos Minerais - isto porque o banco determina que as empresas tenham no máximo $20 \%$ de perda nas redes de distribuição de água. Só em São Paulo, em 2001, as perdas se situavam em $30 \%$.

A degradação ambiental é um dos aspectos mais críticos do processo de deterioração causado direta e indiretamente pelo homem. Regiões que antes tinham quantidades em recursos hídricos, hoje começam a dar sinais de escassez, e a explicação é o desperdício com a exploração excessiva, o assoreamento dos rios e a poluição das fontes. E todos esses problemas têm origem, quase sempre, na explosão da agricultura industrial que serve para alimentar os milhões de habitantes das cidades. É fato que a urbanização e o crescimento desenfreado das cidades aumentam significativamente o consumo e a má utilização de água. 


\section{O QUE FAZER DIANTE DE TANTO DESPERDÍCIO?}

Despoluir a água não é um problema somente técnico, mas também de ordem econômica e social, pois não existem recursos suficientes para se implantar os sistemas de purificação de efluentes líquidos com a tecnologia disponível. Sabe-se que os Estados têm conseguido captar recursos através de bancos internacionais e dar os primeiros passos a favor dos nossos mananciais, como no Rio Grande do Sul, com o Pró-Guaíba (Programa do Estado) e o Guaíba Vive, na capital Porto Alegre, como um referencial quanto ao problema dos recursos hídricos. No entanto, muito ainda precisa ser feito, pois a água é necessária em todos os aspectos da vida. Os recursos de água doce constituem um componente essencial da hidrosfera da Terra e parte indispensável de todos os ecossistemas terrestres e, sua escassez generalizada, a destruição gradativa e o aumento da poluição dos mananciais em muitas regiões do mundo exigem, de todos, a conscientização e mudanças de atitudes em relação às águas. $E$ enquanto muitos esbanjam e desperdiçam, outros já sofrem as consequências da escassez de água. A desigualdade de distribuição e o desperdício são duas fortes razões que explicam, em parte, o porquê de 1,4 bilhão de pessoas - quase cinco vezes a população dos Estados Unidos - não ter acesso à água potável, e a água é um fator primário para a saúde. Sabe-se também que $60 \%$ dos recursos hídricos estão situados em apenas nove países, entre eles o Brasil, mas são 80 países que representam $40 \%$ da população mundial, que sofrem com a escassez de água. No entanto, não significa que os Estados Unidos, o Brasil, a Rússia, a África do Sul ou a China, considerados países ricos em água, não estejam livres de problemas de falta d'água.

Quanto ao desperdício, segundo Rodolfo F. Alves Pena, a agricultura é responsável pela absorção de em média mundial, $70 \%$ das provisões de água, e esse índice passa para 80 a $90 \%$ nos países subdesenvolvidos. A água potável se perde em média $50 \%$ nos vazamentos de sistemas de distribuição e se nada for feito no sentido de mudanças de comportamento, no ano 2025 serão mais de 4 bilhões de pessoas que não terão aceso a esse bem tão precioso e essencial para a vida. 
Portanto, é necessário analisar a questão do não-desperdício da água no meio rural de uma forma integrada, em que vários fatores influenciam para a mudança de hábito dos produtores, em se tratando do uso adequado dos recursos hídricos, como discute Oliveira (2008):

A decisão e opção pelo uso mais eficiente dos recursos naturais em geral e da água em particular deve-se dar de maneira integrada e associada aos instrumentos de gestão em todos os níveis competentes. Só assim será possível alcançar um patamar que possibilite uma adequação da oferta e da demanda com vistas ao uso racional desse recurso tão precioso. (OLIVEIRA, 2008, p.3)

Essa conscientização precisa ocorrer nos diversos âmbitos da sociedade, independente da condição social, cultural e intelectual dos indivíduos. Isso porque hoje, um cidadão europeu consome 150 litros de água por dia, enquanto um indiano tem que se contentar com apenas 25 litros por dia. Um americano consome 3.000 litros de água por dia.

É bom frisar que o desperdício do papel é mais um agravante na derrubada de árvores, como também, o consumo de água, já que, para produzir uma tonelada de fibra virgem, são necessários 44 mil a 83 mil litros de água. É preciso incentivar o uso do papel reciclado, já que, para cada tonelada de papel usado, quase uma tonelada de papel novo pode ser produzida (mais eficiente do que a relação 2-3,5 toneladas de árvores para produzir uma tonelada de papel virgem). O processo de Educação Ambiental deve ser estimulado.

A água doce, um recurso finito, é altamente vulnerável e de múltiplos usos, portanto deve ser gerida de modo integrado com mecanismos eficazes de coordenação e de implementação. Nos planos para sua utilização, deve-se enfatizar a proteção, a conservação e o manejo sustentável e racional baseados nas necessidades e prioridades de cada comunidade. A avaliação dos recursos hídricos constitui a base prática para seu manejo integrado e sustentável, bem como um exame equilibrado das necessidades da população e do meio ambiente. 
Por todas as razões aqui apresentadas, é preciso ter em mente que a água é a mercadoria mais preciosa desse século, isso, no entanto, não significa que se deva transformar a "fonte da vida" em sistema monetário, gerador de tantos conflitos, mas sim unir esforços em prol do consumo consciente e da preservação desse recurso vital para a garantia da qualidade de vida das futuras gerações.

\section{CONSIDERAÇÕES FINAIS}

A sustentabilidade é a relação existente entre os sistemas da economia humana e o meio ambiente. As ações dos homens devem estar em sintonia com o meio ambiente, garantindo a manutenção e a preservação para assim manter a diversidade, a complexidade e o funcionamento do sistema ecológico que nos mantêm vivos. $\mathrm{E}$ pensar de forma sustentável faz-se necessário, pois os recursos naturais são finitos. Além disso, a qualidade dos recursos vem ficando cada vez pior devido ao aumento da população e à ausência de políticas públicas voltadas para a sua preservação. Como exemplo, estimase que aproximadamente doze milhões de pessoas morrem anualmente por problemas relacionados com a qualidade da água.

A única maneira pela qual a maioria dos países pode tratar a crescente poluição de seus recursos hídricos é a implantação de estratégias integradas de administração, que não só ajudem a limpar os cursos d'água, mas, em primeiro lugar, também impeçam a poluição. Até agora, bem poucos países conseguiram realmente por em prática tais mudanças. É preciso estar alerta. Teremos de evitar o desperdício, interromper os processos poluidores e criar novas maneiras de controle, captação e distribuição.

É preciso uma resposta cultural e ética. A situação pela qual o mundo está passando, nada mais é do que um estilo de vida mais sofisticado, onde o que se quer se "deve ter", ocasionando assim a aceleração das fábricas e indústrias que estão entre as maiores usuárias da água só perdendo para a agricultura e uso doméstico. No século $X X$ a população cresceu três vezes, enquanto o consumo de água aumentou seis. Mesmo nós, brasileiros, que temos $16 \%$ de toda a água do mundo, estamos sofrendo 
com racionamentos devido à má administração dos recursos e da infraestrutura inadequada. Os países áridos enfrentam desafios mais assustadores como o Oriente Médio, onde existem áreas em que a escassez limita o crescimento sócio- econômico.

Medidas de manejo conjunto do uso da terra e dos recursos hídricos devem se dar com mais frequência para que seja aumentada a eficiência do uso da água de irrigação evitando assim a erosão do solo, os alagamentos, a sedimentação, a salinização e os efeitos nocivos dos agrotóxicos e fertilizantes nos organismos. Além do que, a degradação ambiental gerou uma patologia ambiental emergente, e doenças como a cólera, e a dengue, tornaram a aparecer com mais força, ocasionadas pela contaminação do ar, da água e dos solos, como também pelo uso de substâncias tóxicas e perigosas, como pesticidas e outros produtos de cuidados especiais. Como vimos até aqui, a degradação não é somente do meio ambiente, mas também do ser humano, cujos valores se perdem, onde as necessidades já não são as básicas e sim as supérfluas, onde estar errado é ser o certo. É aí que vamos ver a Educação Ambiental como meio prioritário para alcançar os fins de um desenvolvimento sustentável. A Conferência de Tbilisi realizada em 1977, tratando da educação ambiental em âmbito internacional, faz ver a EA como a formação de uma consciência fundada numa nova ética que resistirá a toda e qualquer exploração. É disso que a humanidade precisa, dar uma guinada em suas ações, em seus investimentos, em suas atitudes, em seus valores, para perceber que não é só pensando em si que conseguirá dar um futuro sadio às suas gerações.

Sabemos que é o homem o principal causador de tanto desequilíbrio. O homem perturbou tão completamente o meio natural onde se moveu que já não sabe qual o seu lugar nesse sistema, a não ser, é claro, como fator de desordem. Até agora nossas tentativas de dominar o meio consistiram em simples reformas da paisagem, realizadas torpe e irrefletidamente; enquanto outras atividades humanas produziram efeitos secundários nocivos, imprevistos e mal compreendidos. Todos os oceanos já foram poluídos pelo ser humano, a atmosfera e até as remotas camadas glaciais. A maior parte dos rios está mais ou menos poluída e muitos deles, como o rio Tietê e o Tibre foram transformados em esgoto a céu aberto. Barbie Nadeau, jornalista do 
Newsweek em 2002 esteve em Roma e dá seu depoimento sobre o Tibre “... Flutuam peixes mortos dizimados não se sabe pelo quê. O mau cheiro está em toda parte, um resíduo oleoso faz com que as enguias e as carpas mortas brilhem" e conclui: "...Se um rio é a linha simbólica da vida de uma cidade, então Roma está numa situação bastante ruim". O caso não é dominar o meio, mas sim saber se a natureza pode ser preservada com certa aparência de ordem e se a civilização é capaz de sobreviver à transformação que provoca na natureza. A evolução cultural levou-nos aos poucos a reconhecer que a humanização do planeta só pode ser bem sucedida se as leis ecológicas fundamentais forem respeitadas.

É hora de se começar a pensar em mudança de hábitos. De sentir que formamos, juntos, uma só corrente; se quebrar um elo, a corrente não terá mais sentido. Todos precisam de todos. Os sábios indianos, há milhares de anos, já diziam que o todo está contido nas partes e, por mais que as coisas pareçam diversificadas e plurais, na verdade, são aspectos de uma mesma e única realidade. Eis aí uma sentença a ser meditada, por todos nós, para que possamos entender a dinâmica da vida e ver que não existe o eu e sim, o nós. Até agora a natureza tem sido utilizada gratuitamente, e, graças a ela produzimos e vivemos. No entanto, no panorama do crescimento da população mundial ela não tem tido reconhecido o seu devido valor.

Em relação à irrigação, responsável pelo desperdício e consequente comprometimento das nascentes, para minimizar os impactos do seu uso inadequado, Rebouças (2001) enfatiza que é necessário um planejamento mais eficaz e racional do uso da irrigação e otimização dos equipamentos utilizados. Podendo reduzir inclusive gastos com a energia elétrica.

Outra prática recente no Brasil e que vem ganhando força é a utilização da água de reuso para suprir a necessidade de irrigação de diversas culturas alimentares. Hespanhol (2002) complementa que em diversos países em que se utilizam essa técnica a produtividade aumenta de forma significativa quando bem planejadas.

Qualquer forma de uso eficiente da água visando minimizar o desperdício no campo depende diretamente do planejamento feito pelo produtor. O planejamento é 
indispensável no sentido de compatibilizar os vários usos da água, viabilizando os diferentes setores produtivos, monitorando a quantidade e a qualidade dos recursos hídricos, melhorando os níveis de eficiência global de uso (PAZ et al., 2000).

Segundo (FURRIELA,2001) o primeiro grande desafio que se coloca não só para o produtor rural, mas também para toda a humanidade é a tomada de consciência de que não existe um suprimento inesgotável de água potável no planeta. Algumas medidas devem ser promovidas para garantir o suprimento de água em quantidade e padrões aceitáveis. O grande desafio da atualidade reside em reduzir o nível de degradação da água por meio de medidas como conservação, melhoria do saneamento básico, redução da utilização de pesticidas, produção industrial mais limpa e gerenciamento do consumo.

Cada dia fica mais evidente a necessidade de perceber a água como um bem econômico, em que sua gestão deverá basear-se em princípios de eficiência econômica, de forma que satisfaça a procura sob uma ótica de sustentabilidade.

Acrescenta ainda que é necessário estabelecer uma nova forma de pensar e agir, adotando diferentes hábitos, usos e costumes, onde o objetivo geral seja o crescimento econômico, fundamentado no consumo sustentável da água, promovendo assim a proteção dos mananciais ainda conservados e a recuperação daqueles já prejudicados, ressalta ele que isso apenas não basta, sendo preciso fazer muito mais para alcançar esse objetivo deve-se, portanto tratar a água como uma prioridade social e ambiental, uma vez que é preciso cuidar dos recursos hídricos brasileiros, pois a crescente necessidade de água mundial trará ao país a possibilidade de alavancar seu crescimento e desenvolvimento, passando a deter um insumo essencial à vida e a qualquer atividade produtiva.

\section{REFERÊNCIAS BIBLIOGRÁFICAS}

AGENDA 21. The Earth Summit Strategy to save our Planet. Ed. Daniel Sitarz, Earthpress, 321p. Boulder Colorado, 1994. 
AGÊNCIA NACIONAL DAS ÁGUAS. Disponível em: <www.ana.gov.br> Acesso em: $20 / 07 / 2019$

Baía de todas as águas - Preservação e Gerenciamento Ambiental na Bacia Hidrográfica do Guaíba - Pró-Guaíba, RS/1998.

EBC. Disponível em: <www.ebc.com.br/.../mais-de-75-das-florestas-primarias-domundo-nao-existem-mais >Acesso em:19/07/2019

FURRIELA, R. B. EDUCAÇÃO PARA O CONSUMO SUSTENTÁVEL. Ciclo de Palestras sobre Meio Ambiente - Programa Conheça a Educação do Cibec/InepMEC/SEF/COEA, 2001.

HESPANHOL, I. Potencial de Reuso da Água No Brasil, Agricultura, Industria, Municípios, Recarga de Aquíferos. RBRH- Revista Brasileira Dos Recursos Hídricos. Vol. 7 n. 4, 2002

JUSBRASIL. Disponível em: <https://www.jusbrasil.com.br/topicos/10603350/artigo90-do-decreto-n-24643-de-10-de-julho-de-1934> Acesso em 20/07/2019

MUNDO DA EDUCAÇÃO. $<$ https://mundoeducacao.bol.uol.com.br/geografia/consumo-agua-no-mundo.htm> Acesso em 12 de setembro de 2018.

OLIVEIRA, E. C. A Gestão Dos Recursos Hídricos Sob a Perspectiva da Descentralização. ANAP BRASIL - REVISTA CIENTÍFICA, ano 1 no 1, 2008.

PORTAL FMU. Disponível em: <https://portal.fmu.br/reciclagem-no-brasil-panoramaatual-e-desafios-para-o-futuro/> Acesso em: 20/07/2019

PUC RS. Disponível em:

$<$ www.pucrs.br/edipucrs/online/planetaagua/planetaagua.pdf> Acesso em: $20 / 07 / 2019$ 
REVISTA EDUCAÇÃO AMBIENTAL EM AÇÃO. Disponível em: $<$ http://www.revistaea.org/artigo.php?idartigo=1271> Acesso em: 17/07/2019

REBOUÇAS, A. C. Água e desenvolvimento rural. ESTUDOS AVANÇADOS, 2001.

REBOUÇAS, A.C. Água no Brasil: Abundância, Desperdício e Escassez.BAHIASalvador, v. 13, n. ESPECIAL, p. 341-345, 2003 ANÁLISE \& DADOS

SILVA,J. S. Água e Agricultura Irrigada. Palestra-Seminário Agricultura Irrigada Com Desenvolvimento Sustentável-Universidade Federal De Uberaba-Em 24-09-2009. Disponível em: http:www.irrigacao.org.brdocdownloadAgua\%20Agricultura\%20Irrigada_JoseSilverio. pdf.. Acessado em: 20/07/2019

TUCCI, C. E. M. Gestão da água no Brasil. Brasília: UNESCO, 2001. 156p.(1. Hidrologia - Brasil II. Hespanhol, Ivanildo III. Cordeiro Netto,

VICTORINO, C. J. A. Planeta água morrendo de sede: uma visão analítica na metodologia do uso e abuso dos recursos hídricos. Porto Alegre: EDIPUCRS, 2007.231 p. (1. Água - Uso. 2. Água - Qualidade. 3. Recursos).

Enviado: Junho, 2019.

Aprovado: Agosto, 2019. 